\title{
Resident Attitudes Towards Tourists and Tourism Growth: A Case Study From the Middle East, Dubai in United Arab Emirates
}

Esmat Zaidan ${ }^{1}$, Ph.D, Jason F. Kovacs ${ }^{2}$, Ph.D.

\begin{abstract}
The rapid development of tourism worldwide is giving rise to many anxieties about the actual as well as potentially negative consequences of tourism on host societies. However, despite such concerns, much of the academic research on tourism remains grounded in economic analysis with far less attention being paid to assessing the socio-cultural impacts of tourism, whether real or perceived. The neglect in this regard is particularly acute when it comes to research on the rapidly expanding tourism industry in the United Arab Emirates. This paper addresses this research gap by way of examining resident perceptions of tourism in the City of Dubai. In particular, this study, which was based on responses gathered from over 400 Emirati citizens, explores local attitudes to further tourism growth as well as resident perceptions of the cultural, economic, and behavioural similarities and differences of tourists and themselves. The general findings are then situated within a conceptual framework (Irridex model) designed to show the varying levels of tolerance of a host population to changes in tourist numbers.
\end{abstract}

Key words: Tourism, social carrying capacity, resident perceptions, survey, Dubai

\section{Introduction}

Tourism is one of the fastest growing economic activities worldwide. However, many questions have been raised concerning the desirability and sustainability of policy initiatives that promote further tourism growth (Wall \& Mathieson, 2006). The social and cultural effects of tourism, in particular, are becoming pressing concerns alongside more obvious environmental ones. However, to date academic attention remains largely focused on the economic contributions of tourism despite longstanding calls for more balanced research perspectives that critically investigate tourism's impacts (Mathieson \& Wall, 1982).

Although the Middle East has been identified as one of the least developed tourism regions in the world, rapid urbanization and modernization in some of the wealthier Arab countries has been accompanied by remarkably fast growing tourism industries. This is certainly the case in the United Arab Emirates (UAE) where tourism has been given a central role in recent economic and strategic development plans with the aim of helping to diversify the economy and reduce the country's dependency on fluctuating oil prices (Stephenson \& Ali-Knight, 2010).

Dubai, the UAE emirate that was one of the least developed regions in the Middle East some four decades ago (Sharpley, 2008; Zaidan, 2015a) is today characterized by a landscape of luxury residences, the biggest shopping complexes, tallest 
steel towers, most luxurious hotels (e.g. 7-star Burj Al Arab hotel), imaginative manmade islands, and creative theme parks (Smith, 2010). Not surprisingly, modern Dubai is already well positioned on the international tourism map as a top world destination (Bagaeen, 2007; Sharpley, 2008; Zaidan, 2015b). Nonetheless, the government of Dubai is seeking to expand the city's tourism sector even further as outlined in its recently approved strategic tourism vision (Dubai Vision 2020). The vision set forth sees Dubai welcoming 20 million tourists per year by 2020, which represents a tripling of the economic contribution that tourism currently adds to the emirate's economy (DTCM, 2013).

A positive upward trend in tourist visits and hotel occupancy was already noticeable even before the vision was given formal approval in early 2013. For example, Dubai welcomed more than 7.9 million visitors during the first nine months of 2013, which already represented a $9.8 \%$ growth rate compared to the previous year (Government of Dubai, 2013). A factual review of tourism development in Dubai, including an analysis of arrivals is presented in Figure 1.

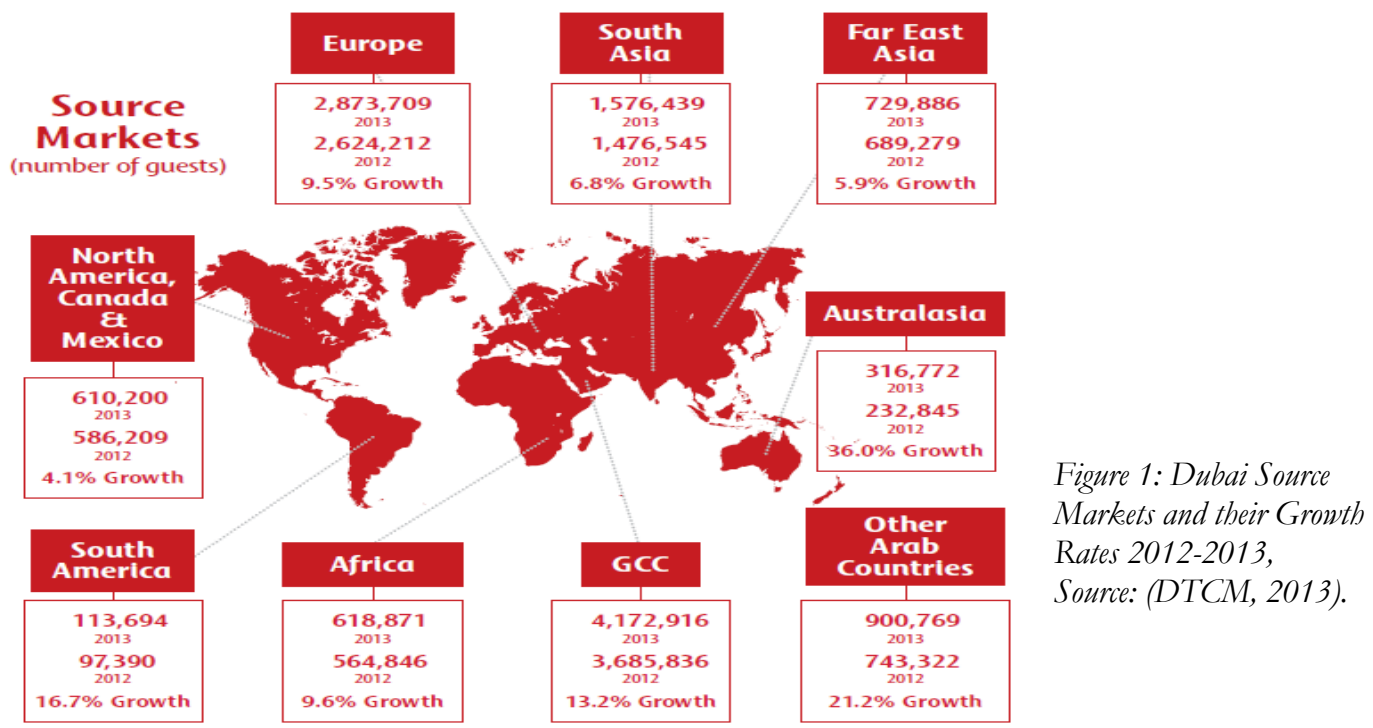

On the other hand, The DTCM (Dubai Tourism and Commerce Marketing) published its figures on their website of Government Dubai for 2015. The Emirate welcomed 12.6 million visitors in 2015, a 5.6\% increase over 2014. 54.2 million nights were documented during the year, meaning $7.4 \%$ more than the previous year. Travelers were more numerous as the increase could be observed from all continents. They also stayed longer as the average length of stay increased from 3.78 to 3.84 days on a comparable period. The neighboring Emirates with 4.3 million tourists remains the main source market Europe with 2.9 million visitors, and Southern Asia (1.8 million tourists) are second source continents. In terms of country, Saudi Arabia is once again the prime source market, followed by India $(+12.2 \%)$ and the United Kingdom $(+11.3 \%)$. United States follows, Iran, the Sultanate of Oman, China -which ascended three ranks $(+24.9 \%$ growth), Kuwait, Russia and Germany. Furthermore, exempting 13 more European 
countries from visa requirements to enter UAE applied since March 2014 has significantly contributed to the growth in number of visitors from this continent $(+2.8 \%$ to 2.9 million tourists) (Government of Dubai, 2015).

Furthermore, according to the MasterCard Global Destination Cities Index (2014), Dubai ranks fifth among top global destinations for international travellers, rising two slits from the seventh position in 2013 (See Figure 2 \& Table 1). Dubai, not only jumped ahead of New York and Istanbul to take the fifth place, but it already welcomed almost 12 million overnight international visitors in 2014, meaning rising by 7.5 per cent from 2013. Paris and Singapore, for example, with $1.8 \%$ and $3.1 \%$ growth rates respectively, are both eclipsed by Dubai's 7.5\% growth rate. If their present growth rates are to continue, then Dubai would surpass both Paris and Singapore within five years only (MasterCard Global Destination Cities Index, 2014).

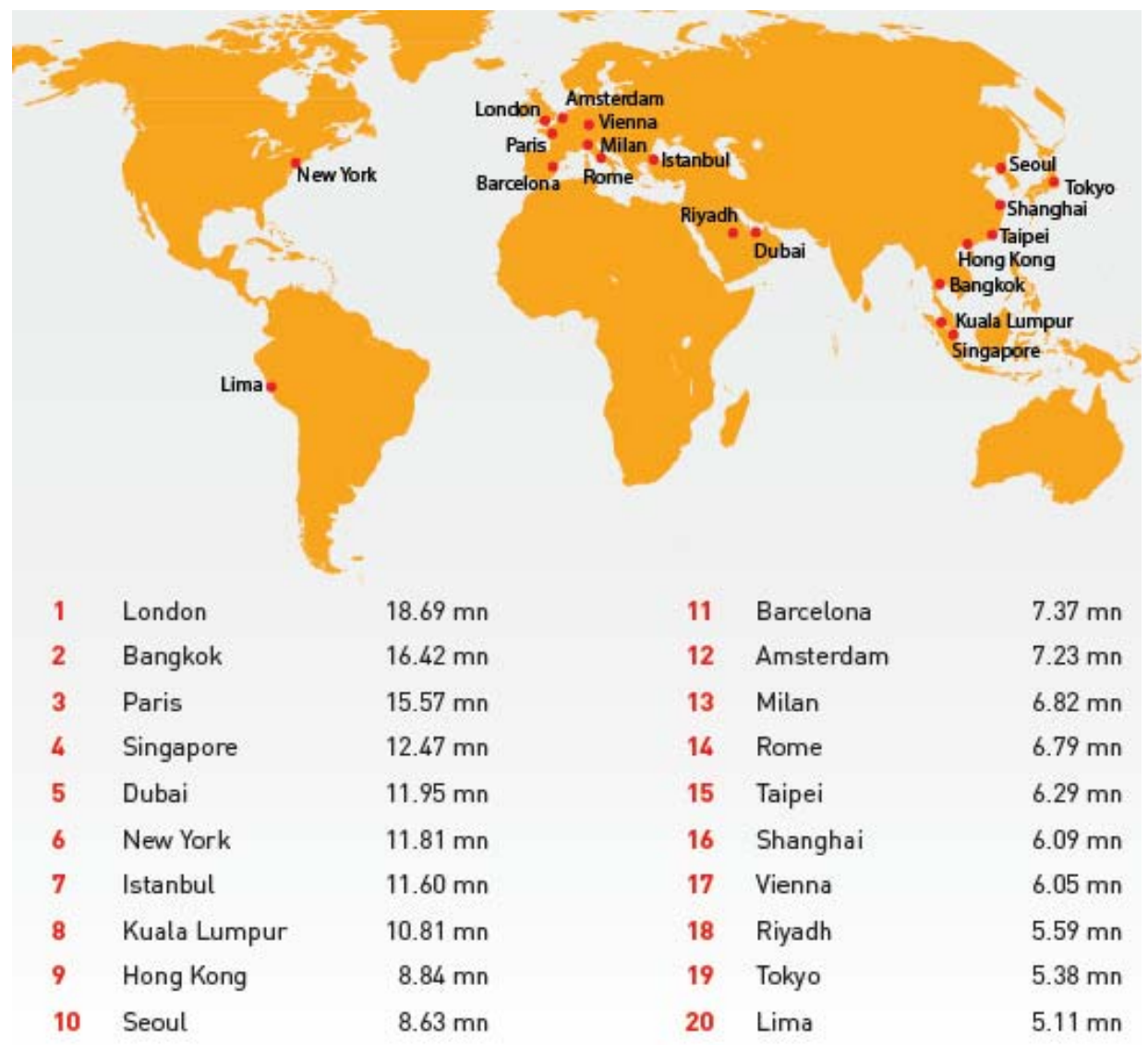

Figure 2: Global Top 20 Destinations for International Travellers for 2014.

Source: (MasterCard Global Destination Cities Index, 2014).

The numbers of overnight international visitors can also be demonstrated on a per resident basis for each of the top twenty destination cities to show the degree of their impacts. Whereas the ratio have grown for top 20 destination cities between 2010 and 
2014, Dubai has the highest ratio of 4.8 visitors per resident, up from 4.2 in 2009 (MasterCard Global Destination Cities Index, 2014).

Table 1: Global Top 20 Destination Cities by International Overnight Visitors (2010-2014)

\begin{tabular}{|c|c|c|c|c|c|c|c|c|c|}
\hline \multirow{2}{*}{\multicolumn{2}{|c|}{$\begin{array}{l}\text { Destination } \\
\text { City }\end{array}$}} & \multirow[b]{2}{*}{ Country } & \multicolumn{6}{|c|}{ Visitors (millions) } & \multirow{2}{*}{$\begin{array}{l}2014 \\
\text { Visitor } \\
\text { Spend } \\
\text { (US\$ bn) }\end{array}$} \\
\hline & & & 2010 & 2011 & 2012 & 2013 & 2014 & $\begin{array}{l}\% \Delta \\
2013 \& \\
2014\end{array}$ & \\
\hline 1 & London & UK & 14.71 & 15.29 & 14.46 & 17.30 & 18.69 & 8.0 & 19.3 \\
\hline 2 & Bangkok & Thailand & 10.44 & 13.80 & 15.82 & 18.46 & 16.42 & -11.0 & 13.0 \\
\hline 3 & Paris & France & 13.27 & 13.88 & 14.33 & 15.29 & 15.57 & 1.8 & 17.0 \\
\hline 4 & Singapore & Sigapore & 8.80 & 10.14 & 11.11 & 12.10 & 12.47 & 3.1 & 14.3 \\
\hline 5 & Dubai & UAE & 8.41 & 9.20 & 10.16 & 11.12 & 11.95 & 7.5 & 10.9 \\
\hline 6 & New York & USA & 9.43 & 10.27 & 10.60 & 11.08 & 11.81 & 6.6 & 18.6 \\
\hline 7 & Istanbul & Turkey & 6.45 & 7.51 & 8.82 & 9.87 & 11.60 & 17.5 & 9.4 \\
\hline 8 & $\begin{array}{l}\text { Kuala } \\
\text { Lumpur }\end{array}$ & Malaysia & 8.90 & 8.99 & 9.26 & 9.56 & 10.81 & 13.1 & 8.1 \\
\hline 9 & $\begin{array}{l}\text { Hong } \\
\text { Kong }\end{array}$ & China & 8.13 & 8.43 & 8.37 & 8.26 & 8.84 & 7.0 & 8.3 \\
\hline 10 & Seoul & South Korea & 6.06 & 6.56 & 7.51 & 8.24 & 8.63 & 4.7 & 11.5 \\
\hline 11 & Barcelona & Spain & 6.18 & 6.89 & 6.91 & 7.18 & 7.37 & 2.7 & 11.2 \\
\hline 12 & Amsterdam & Netherlands & 5.86 & 6.07 & 6.10 & 6.74 & 7.23 & 7.2 & 4.4 \\
\hline 13 & Milan & Italy & 5.83 & 6.59 & 6.88 & 6.85 & 6.82 & -0.4 & 5.3 \\
\hline 14 & Rome & Italy & 6.65 & 6.66 & 6.82 & 6.63 & 6.79 & 2.5 & 5.6 \\
\hline 15 & Taipei & Chinese Taipei & 3.52 & 3.96 & 4.70 & 5.80 & 6.29 & 8.4 & 10.8 \\
\hline 16 & Shanghai & China & 6.67 & 6.18 & 6.04 & 5.66 & 6.09 & 7.6 & 5.3 \\
\hline 17 & Vienna & Austria & 4.64 & 5.08 & 5.38 & 5.67 & 6.05 & 6.8 & 5.6 \\
\hline 18 & Riyadh & Saudi Arabia & 1.82 & 4.16 & 4.83 & 5.52 & 5.59 & 1.3 & 4.1 \\
\hline 19 & Tokyo & Japan & 4.47 & 2.94 & 4.07 & 5.05 & 5.38 & 6.5 & 7.4 \\
\hline 20 & Lima & Peru & 2.07 & 2.94 & 3.94 & 4.91 & 5.11 & 4.1 & 1.8 \\
\hline
\end{tabular}

Source: Adapted from (MasterCard Global Destination Cities Index, 2014).

Despite the rapid growth of tourism, which has helped change the face of Dubai, little scholarly attention has been paid to the social and cultural impacts of this Emirate's westernized approach to tourism development or to local perceptions towards the city's tourism strategy (Zaidan, 2016). Indeed, while a growing body of work can be found on the topics of tourism and destination branding in Dubai (Bagaeen, 2007; Balakrishnan, 2008; Govers \& Go, 2005, 2009; Henderson, 2006, 2007; Junemo, 2004; Meethan, 2011; Sharpley, 2008) few studies have explored the social and cultural attitudes of local residents towards the presence of tourists or to continued tourism growth and its potential consequences (Zaidan, 2016; Stephenson, 2014; Stephenson \& Ali-Knight, 2010). This paper attempts to address this research gap by exploring resident attitudes in Dubai to the presence of tourists and tourism activities. The findings are contextualized through the application of an appropriate conceptual model.

\section{Context}

Tourism is indivisibly tied up with modernization and has powerful effects on cultures and local societies (Erisman, 1983; Nunez, 1963). In fact, tourism has long been 
perceived as "the enemy of authenticity and cultural identity" (Turner \& Ash, 1975: 197). On the other hand, it has been increasingly recognized that tourism plays an important role in promoting distinctive local, regional and national identities and place images (Osborne, 2002; Osborne \& Kovacs, 2008; Park, 2010, 2011; Park \& Stephenson, 2007; Soper, 2011). Mathieson and Wall (1982: 1) define tourism as simply the "temporary movement of people to destinations outside their normal places of work and residence, the activities undertaken during their stay in their destinations and the facilities created to cater to their needs". Thus, the study of tourism is ultimately about the study of people away from their usual habitat, of the establishments that respond to the requirements of travelers, and of the impacts that these visitors have on the economic and social wellbeing of the host population. Aside from its recognizable contributions to the economy and effects on the natural and built environment, tourism can contribute to marked social and cultural change in a host society (e.g. affecting value systems, traditional lifestyles, individual behaviour, community structure) (Ratz, 2003). Thus, given the potential sociocultural outcomes, there is a need for critical research on host perceptions to tourist activities and tourism growth.

Dubai has spent billions of dollars to build an astounding modern city almost from scratch (Bagaeen, 2007) and continues to invest heavily in this long-term project. Dubai's formula for modernization as well as economic development has included several components: visionary leadership, good regional and international communications, an attractive winter climate and environmental landscape (desert), a central location between Europe and East Asia, high quality infrastructure, low import duties, and the absence of taxes on personal and corporate incomes (Sharpley, 2008). These factors have served to encourage rapid population growth (currently 2.2 million, Government of Dubai, 2014) all the while helping to transform the city into an important global tourism destination (Bagaeen, 2007; Henderson, 2007; Sharpley, 2008; Stephenson \& Ali-Knight, 2010). As pointed out by Stephenson and Ali-Knight (2010), the 2008 Country Brand Index (CBI) already identified the UAE as one of the top three 'rising stars' alongside China and Croatia as global tourism destinations. The ruler of Dubai, His Highness Sheikh Mohammed bin Rashid Al Maktoum, is widely recognized as the driving force behind the Emirate's successful tourism development strategy (Nagraj, 2014). Recently, Sheikh Mohammed, who is the Vice President and Prime Minister of the UAE as well as the head of the Department of Tourism and Commerce Marketing (DTCM) announced Dubai's Tourism Vision for the year 2020 with its bold underlying goal of doubling tourist numbers. Reflecting the recency of Dubai Vision 2020 no studies have yet explored resident attitudes towards the plan for significantly heightened mass tourism or to the perceived consequences that this may have on local culture and quality of life.

\section{Tourists and tolerance}

Provided that the numbers of visitors at a tourist destination and their accumulative impacts stay below a critical level the presence of tourists is generally tolderated by local residents (Wall \& Mathieson, 2006). However, as soon as the critical level is surpassed and economic impacts no longer remain positive, various signs of disatisfaction tend to become apparent within the host population. These signs can be 
measured from slight apathy to extreme xenophobia. The question that must therefore be asked is what is the critical level of tolerance and how can it be determined?

The concept of social carrying capacity is an increasingly important concept in the tourism literature. It is used in reference to questions such as the aforementioned that concern "sustainable tourism." Social carrying capacity, as Boniface and Cooper (2005: 33) define it, is "a measure of the ability of the host community to tolerate tourism." It varies from one destination to another according to the following factors: First, social carrying capacity is influenced by differences in terms of culture and economic conditions between tourists and the host population; host populations usually show greater tolerance to those tourists who are closer to them in appearance, economic characteristics, culture, and language (Mathieson \& Wall). As Reisinger (1994) argues, the larger the distance between the host population and tourists the more noticeable will be the sociocultural impacts. Second, social carrying capacity varies according to the extent to which the tourist destination and the host population are capable of absorbing tourist arrivals both physically and psychologically without overwhelming local facilities and services (Lundberg, 1974: 85). Third, social carrying capacity is influenced by the speed and intensity of tourism development, as well as the approach used. For example, when tourism is integrated gradually into an established economy, the sociocultural impacts are generally insignificant. On the other hand, various undesirable sociocultural impacts are unavoidable when tourism replaces an established economic activity in a shorter period of time (Wall \& Mathieson, 2006).

Many studies that address the factors influencing social carrying capacity are focused on tourism destinations either at the edge or beyond in terms of the critical level of resident tolerance towards visitor arrivals (Matthieson \& Wall; Kerstetter \& Bricker, 2012). However, this study concerns a tourist destination where resident tolerance is so far at an initially high level, although, as it will be argued, this may change in the not too distant future. Before outlining the methodology that was used to survey Dubai's host population it is first necessary to introduce a conceptual model that will be of later use in contextualizing the research findings.

Several conceptual frameworks have been developed to explore and measure the social and cultural impacts of tourism as well as levels of tolerance to different stages of tourism development (for example, Cohen, 1972; Robinson, 1976; Pizam \& Milman, 1984; Mitchell \& de Waal, 2009). A common understanding that informs these conceptual frameworks is that the sociocultural impacts of tourism as well as levels of tolerance within the host population change over time. In particular, these changes and the speed at which they occur may be influenced by structural changes in the tourism industry, the rate of tourism development, and the extent to which local residents are exposed to varying numbers of tourists and tourism activities (Wall \& Mathieson, 2006). For the purpose of this paper, Doxey's Irridex model (1975) is adopted to situate the survey findings. This relatively simple conceptual model is applied since it presents a clear visual trend between levels of tourism development and changes in host population attitudes. In particular, as visualized in Figure 3 and elaborated in greater detail in Table 2 the model suggests that different levels of tension within the host population are correlated with particular stages of tourism growth. More specifically, irritation levels, which range from euphoria to antagonism, are dependent on the number of outsiders 
and the pressures that they pose on the quality of life of local residents. Simply put, as tourism numbers grow so to do levels of tension within the host population. Although acceptance levels are destination specific and the time-based position of each stage is subject to different economic, sociocultural and psychological factors, the Irridex model captures well the widely accepted stages of resident attitudinal changes to tourism growth.

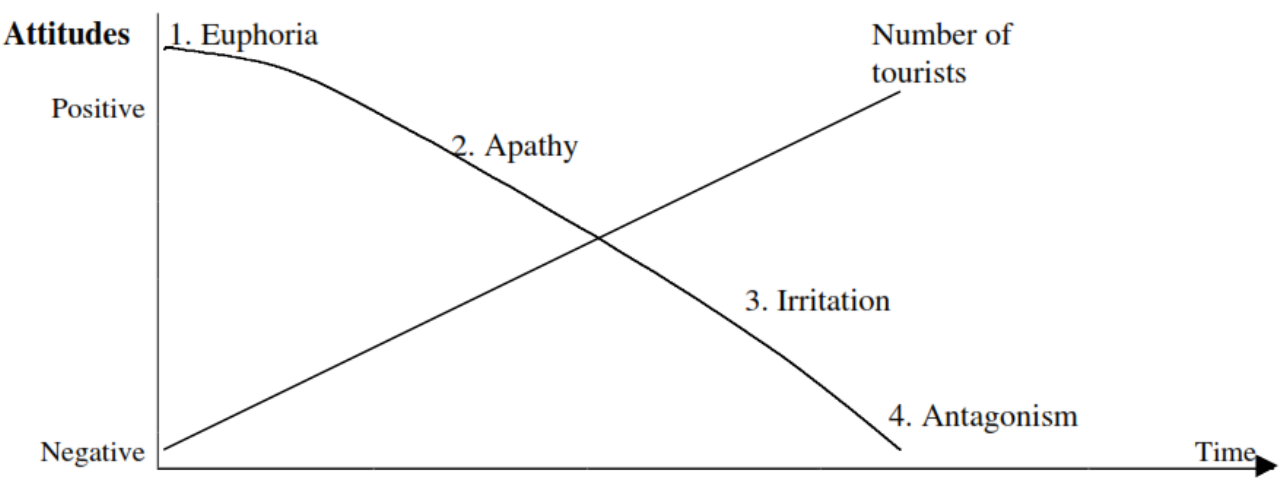

Figure 3. Index of Tourist Irritation (Source: Doxey 1975)

Table 2. Stages of tourist irritation

\section{The level of euphoria}

People are enthusiastic and thrilled by tourism development. They welcome the stranger and there is a mutual feeling of satisfaction. There are opportunities for locals, and money flows in along with the tourist

\section{The level of apathy}

As the industry expands people begin to take the tourist for granted. The tourist rapidly becomes a target for profit-taking, and contact on the personal plane begins to become more formal

\section{The level of irritation}

This will begin when the industry is nearing the saturation point or is allowed to pass a level at which locals cannot handle the numbers without the expansion of facilities

\section{The level of antagonism}

Irritation has become more overt. People now see the tourist as the harbinger of all that is bad (e.g. 'Taxes have gone up because of the tourists'; 'They have no respect for property'; 'They have corrupted our youth'). Mutual politeness has now given way to antagonism and the tourist is 'ripped off'

\section{The final level}

People have forgotten that what they originally cherished was what drew the tourist, but in the scramble to develop they overlooked this and allowed the environment to change. What they now must learn to live with is the fact that their ecosystem will never be the same again. They might still be able to draw tourists but of a very different type from those they welcomed in earlier years. If the destination is large enough to cope with mass tourism it will continue to thrive

Source: Doxey 1976: 26-27 


\section{Methodology}

Primary data was collected during the spring and summer months of 2015 through a self-administered survey. Participants were selected based on a convenience sampling method. Potential respondents, all of whom were Emirati citizens (i.e. permanent residents), were approached in the streets, malls, coffee houses and restaurants of Dubai by four student research assistants and asked to participate in the study after the research objectives were explained to them. The questionnaire contained closed questions, such as multiple choice-type questions and five-Likert scaling questions.. In total 462 questionnaires were filled out, of which 34 were later discarded because they were not completed satisfactorily. The study is thus based on a sample of 428 respondents.

\section{Objective and Findings}

The main objective of this study is to examine resident perceptions in Dubai to tourism and to situate the survey findings within an appropriate conceptual framework, Doxey's Irridex model. The demographic characteristics of participants in the sample are shown in Table (3).

Table 3: Socioeconomic characteristics of participants in the sample.

\begin{tabular}{|c|c|c|c|}
\hline & $\begin{array}{l}\text { Socioeconomic } \\
\text { Characteristics }\end{array}$ & Number of responses & Percent of Total \\
\hline \multirow[t]{2}{*}{ Gender } & Male & 216 & 50.5 \\
\hline & Female & 212 & 49.5 \\
\hline \multirow[t]{2}{*}{ Marital Status } & Married & 230 & 53.7 \\
\hline & Single & 198 & 46.3 \\
\hline \multirow[t]{5}{*}{ Age } & $20-30$ & 230 & 29.7 \\
\hline & $31-40$ & 135 & 32.8 \\
\hline & $41-50$ & 94 & 22.9 \\
\hline & $51-60$ & 32 & 7.8 \\
\hline & 60 and over & 28 & 6.8 \\
\hline \multirow[t]{6}{*}{ Number of Children } & 0 & 142 & 33.4 \\
\hline & 1 & 90 & 21.2 \\
\hline & 2 & 127 & 29.9 \\
\hline & 3 & 45 & 10.6 \\
\hline & 4 & 10 & 2.4 \\
\hline & 5 or more & 11 & 2.6 \\
\hline \multirow[t]{5}{*}{ Education } & Primary School & 11 & 2.6 \\
\hline & Middle School & 37 & 8.7 \\
\hline & High School & 136 & 31.9 \\
\hline & University & 181 & 42.5 \\
\hline & Postgraduate- & 61 & 14.3 \\
\hline
\end{tabular}




\begin{tabular}{llll} 
Occupation & university & & \\
& Self-employed & 69 & 16.3 \\
& Government & 168 & 39.6 \\
& Private sector & 65 & 15.3 \\
& Student & 71 & 16.7 \\
& Retired & 7 & 1.7 \\
& Unemployed & 35 & 8.3 \\
& Other & 9 & 2.1 \\
Annual Income (USD & Less than 8,000 & 72 & 17.9 \\
\$) & $8,000-11,000$ & 138 & 34.2 \\
& $12,000-15,000$ & 116 & 28.8 \\
& $16,000-19,000$ & 50 & 12.4 \\
& More than 19,000 & 27 & 6.7 \\
\hline
\end{tabular}

$\mathrm{N}=428$

As will be seen in greater detail, the success of tourism development in attracting millions of tourists to Dubai has contributed to the host population's generally positive attitude towards tourism. Indeed, the vast majority $(90.66 \%)$ of the 428 survey participants indicated that they are in favour of the presence of tourists and tourism activities (Table 4). This finding suggests that the majority of Dubai's Emirati community accepts tourism and its impacts either because of the significant benefits it is bringing to their city or perhaps because they can see no other option towards reversing the trend. Since it is recognized that the success of tourism depends on the attitudes and behaviours of the host society this finding would also seem to indicate that there is likely some room left for further tourism development without provoking significant tension within Dubai's host population. To test this assumption our study addressed resident perceptions towards tourist numbers, resident attitudes towards Dubai's tourism strategy (e.g. vision, achievements), and resident perceptions on differences between tourists and themselves (e.g. behaviour, culture).

Table 4. Attitudes towards Tourists and Tourism Activities

\section{Resident attitudes on presence of tourists and tourism Response Percentage activities}

\begin{tabular}{lll}
\hline Strongly supports tourist presence and tourism activities & 183 & 42.8 \\
$\begin{array}{l}\text { Slightly supports tourist presence and tourism activities } \\
\text { No support and no opposition }\end{array}$ & 205 & 47.9 \\
$\begin{array}{l}\text { Does not support tourist presence and tourism activities } \\
\text { but accepts them }\end{array}$ & 34 & 7.9 \\
$\begin{array}{l}\text { Strongly opposes tourist presence and tourism activities } \\
\text { Total }\end{array}$ & 6 & 1.4 \\
\end{tabular}




\subsection{Resident perceptions towards tourist numbers}

Dubai is one of the fastest growing tourism destinations of the early twenty-first century and attracts millions of visitors each year. However, as revealed by the survey, the majority of the respondents $(59.4 \%)$ believe that the number of tourists visiting their city is currently appropriate (Table 5). The survey also showed that $20.8 \%$ of respondents believe that tourism should increase to a certain extent while only $9.2 \%$ believe that it should increase significantly. On the other hand, only about a tenth of the respondents believe that the number of tourists should decrease either somewhat $(4 \%)$ or to a significant degree $(6.6 \%)$.

Table 5. Perceptions on the Number of Tourists

\begin{tabular}{lll}
\hline Resident perceptions about tourist numbers & Response & Percentage \\
\hline It should increase significantly & 39 & 9.2 \\
It should increase somewhat & 88 & 20.8 \\
It is appropriate & 252 & 59.4 \\
It should decrease somewhat & 17 & 4.0 \\
It should decrease significantly & 28 & 6.6 \\
Total & 424 & 100 \\
\hline
\end{tabular}

To further gauge the host population's perception of tourism the survey included the following set of questions:

- $\quad$ Do you believe that development in Dubai is geared more to the needs of tourists as opposed to locals?

the vision outlined in Dubai Vision 2020?

Are you satisfied with

- Do you believe that Dubai would be what it is today without tourism development?

- Do you believe that tourism is essential for continued prosperity in Dubai?

The responses to these questions as shown in Table 6 indicate that the majority $(62.6 \%)$ of survey participants believe that development in Dubai serves the needs first and foremost of the tourist rather than the local resident. On the other hand, the majority of survey respondents $(64 \%)$ indicated that they believe Dubai would not be what it is today without tourism development. Remarkably $83.3 \%$ of respondents indicated that tourism development is essential for the city's continued prosperity. However, $56.7 \%$ of the respondents were satisfied with Dubai's tourism goal of attracting some 20 million visitors by 2020 , while $43.3 \%$ are not.

Table 6. Resident Attitudes on Further Tourism Development and Increased Numbers of Tourists

\begin{tabular}{lll}
\hline \multicolumn{2}{l}{ Do you believe that development in Dubai is geared more for tourists than for locals } \\
\hline & Response & Percentage \\
Yes & 268 & 62.6 \\
No & 160 & 37.4 \\
Total & 428 & 100
\end{tabular}


Do you believe that Dubai would be what it is today without tourism development

$\begin{array}{lll}\text { Yes } & 154 & 36.0 \\ \text { No } & 274 & 64.0 \\ \text { Total } & 428 & 100\end{array}$

Do you believe that tourism is essential for a continued prosperity in Dubai

$\begin{array}{lll}\text { Yes } & 353 & 83.3 \\ \text { No } & 71 & 16.7 \\ \text { Total } & 424 & 100\end{array}$

Are you satisfied with Dubai Tourism Vision 2020 of attracting 20 million visitors

\begin{tabular}{lll} 
Yes & 241 & 56.7 \\
No & 184 & 43.3 \\
Total & 425 & 100 \\
\hline
\end{tabular}

\subsection{Perception of the differences between tourists and the host society}

The critical point of tolerance with respect to the host society and tourism varies according to several factors including the cultural and economic differences between tourists and local residents. The survey used in this study explored such perceived differences via four specific categories: general behaviours, financial conditions, culture, and leisure activities.

\subsection{General behaviour}

The majority of the participants $(69.9 \%)$ believe there to be a significant difference between themselves and tourists in terms of behavioural differences (Table 7), a finding that is consistent with research findings elsewhere (Ratz, 2000). Resident perceptions about general behaviours may be simply explained by differences in the social roles of the hosts and guests. As Mathieson and Wall (1982: 135) point out, in sharp contrast to the typical resident "the tourist is mobile, relaxed, free-spending, enjoying his leisure and absorbing the experience of being in a different place."

Table 7. Perceptions of Behavioral Differences between Host Population and Tourists

\begin{tabular}{lll}
\hline \multicolumn{2}{l}{ Resident perceptions on differences in general behavior between Emiratis and tourists } \\
\hline & Response & Percentage \\
Significant difference & 299 & 69.9 \\
Some difference & 121 & 28.3 \\
No difference & 8 & 1.8 \\
Total & 428 & 100 \\
\hline
\end{tabular}

\subsection{Financial conditions}

Given that the United Arab Emirates is ranked sixth in the world by GDP per capita (Forbes.com) it is not surprising that the survey results reveal that the majority $(69.9 \%)$ of Emirati respondents believe that there is no difference between themselves and tourists in terms of financial conditions (Table 8) despite the fact that the UAE has 
become a popular destination for the "ultra-wealthy" (Jordan-Bychkov et al., 2014). Only $17.9 \%$ of survey respondents indicated that there is some difference while even fewer $(12.2 \%)$ believed there to be a significant difference. Of relevance to the findings of this study, McIntosh, Goeldner and Ritchie (1995) note that resentment and stress is often minimized when economic inequality is not significant.

Table 8. Resident Perceptions towards Financial Conditions of Tourists Compared to Local Citizens

Perceptions about differences in financial situation between Emiratis and tourists

\begin{tabular}{lll}
\hline & Response & Percentage \\
Significant difference & 52 & 12.2 \\
Some difference & 76 & 17.9 \\
No difference & 297 & 69.9 \\
Total & 425 & 100 \\
\hline
\end{tabular}

Material inequity often exists and is noticeable in tourist spending and attitudes. According to the UNEP (2014), many tourists come from societies with higher incomes and higher consumption patterns than those associated with the tourist destination. This is particularly the case in less developed countries where there is a growing distinction between the "haves" and "have-nots." Such economic inequality may create cultural conflicts in addition to social and ethnic tensions. For Emiratis in Dubai, the case is entirely different since the UAE has been classified as a high-income country since 1995 (Elessawy and Zaidan, 2014); thus, they have similar consumption patterns to American and Western European tourists as well as tourists from other Gulf Cooperation Council (GCC) member countries (Bahrain, Kuwait, Oman, Qatar, Saudi Arabia).

\subsection{Culture}

The majority of respondents $(62.4 \%)$ indicated that there are significant cultural differences between themselves and tourists (Table 9). In addition, 35.9\% of survey respondents believe that there is only some difference while a mere $1.7 \%$ indicated that there are no differences in culture.

Table 9. Perceived Differences in Culture between Locals and Tourists Perception about the differences in culture between Emiratis and tourists

\begin{tabular}{lll}
\hline & Response & Percentage \\
Significant difference & 261 & 62.4 \\
Some difference & 150 & 35.9 \\
No difference & 7 & 1.7 \\
Total & 418 & 100 \\
\hline
\end{tabular}

The high percentage of respondents indicating that there are significant cultural differences between tourists and the host population owes to the fact that the UAE is an Islamic country. Thus, the cultural distance between tourists, particularly from North America and Europe, and local residents is significant. That said, more than one third of 
the Emirati residents believe that there is "some" difference rather than "significant" difference. This finding may be explained by the fact that while westerners constitute a significant proportion of the tourist population Saudi Arabia is the top tourism source market (see Table 2) with more than one million Saudis visiting Dubai last year alone. In addition, the other GCC member countries (Kuwait, Oman, Qatar, Bahrain) are situated within the top twenty tourism source markets for Dubai.

\subsection{Leisure activities}

The majority of the respondents (44.4\%) believe that there are no differences between tourists and themselves in the type of leisure activities undertaken in Dubai (Table 10). This may be explained by the high incomes enjoyed by Emiratis in general in relation to the average incomes of the countries that are generating tourists for Dubai. Simply put, unlike in many developing countries, economic inequality in Dubai does not really exist between tourists and locals. Consequently, tourists and local Emirati residents generally share the same level of expenditures on all types of leisure activities.

Table 10. Resident Perceptions on Differences in Leisure Activities between Locals and Tourists

\begin{tabular}{lcc}
\hline \multicolumn{2}{c}{ Perception about differences in types of leisure activities between } & Emiratis and tourists \\
\hline & Response & Percentage \\
Significant difference & 79 & 18.8 \\
Some difference & 155 & 36.8 \\
No difference & 187 & 44.4 \\
Total & 421 & 100 \\
\hline
\end{tabular}

\section{Discussion}

The survey findings from this study offer several clues to the future challenges that further tourism growth will pose to the quality of life of Dubai's residents. To begin, the survey results reveal that Dubai's Emirati residents currently have a positive attitude towards the visitors to their city, thus the majority are in favour of continued tourism development. Given the significant benefits (e.g. improved image of Dubai to outsiders; significant job creation; improvements in infrastructure; increased numbers of tourism facilities, shopping venues and leisure attractions) that are associated with Dubai's recent positioning on the international level as top tourist destination this survey finding was not unexpected. Moreover, this finding was complemented by subsequent survey results. In particular, the majority of respondents indicated that Dubai would not be what it is today without tourism and that tourism was essential for the Emirate's continued prosperity. Considered together these findings indicate that the irritation level of Dubai's resident population remains low, and that it likely borders the levels of euphoria and apathy in Doxey's classic Irridex model. That said, the participants of the survey also perceived the current number of tourists in the city to be "appropriate". Therefore, a remarkable increase in tourist numbers as envisioned in Dubai Vision 2020 was not surprisingly viewed quite unfavourably by most residents surveyed. Indeed, the current enthusiasm and level of tolerance for the tourists' presence may begin to quickly fade in 
the coming years once the number of tourists exceeds the critical threshold in terms of the city's social carrying capacity.

As indicated at the beginning of this paper the critical point of tolerance towards tourism varies from one host community to another. It is influenced by a number of factors. These factors, which for the most part pertain to the current tourism trend in Dubai, include: the cultural and economic differences between the tourists and hosts; the capability of the destination and its population to both physically and psychologically absorb tourist arrivals without undermining local activities; and the rapidity and intensity of tourism development at the destination area, the latter factor of which should be of especial concern given the projected tourism growth in Dubai. Moreover, with respect to the first factor, the findings showed that Emiratis perceive there to be significant differences between themselves and tourists in terms of culture and behaviour, although not to economic background nor to leisure activities. This observation on cultural and behavioural difference needs to be highlighted in light of the proposed doubling of tourist numbers in Dubai and to the growing recognition that cultural differences often manifest themselves in ways that offend members of a host society. The following extract from a recent UNEP (2014) report highlights the problem:

"In many Muslim countries, strict standards exist regarding the appearance and behaviour of Muslim women, who must carefully cover themselves in public. Tourists in these countries often disregard or are unaware of these standards, ignoring the prevalent dress code, appearing half-dressed (by local standards) in revealing shorts, skirts or even bikinis, sunbathing topless at the beach or consuming large quantities of alcohol openly. Besides creating ill-will, this kind of behaviour can be an incentive for locals not to respect their own traditions and religion anymore, leading to tensions within the local community."

The potential problems associated with a growing influx of western tourists as well as to the other negative consequences of mass-scale tourism have also been cited in the small but growing body of literature on place marketing and tourism in Dubai. For example, Stephenson (2014) notes that the development of modern heritage sidesteps the production of ethnically founded heritage experiences. It leads to a process described by Giddens (1994: 92-93) as the "de-traditionalisation of social order." Writing on Dubai's famed artificial Palm Islands, Junemo (2004) states that the symbolism of this particular attraction "does not relate to a specific culture", while Govers and Go (2005: 86) suggest that the image that is currently being promoted to outsiders does not "coherently reflect [Dubai's] true cultural identity." Emiratis will certainly be challenged to accept further changes to the urban landscape of their city and to its associated place identity if tourism and tourism-related developments expand even further. As observed from our survey the majority of respondents already believe that development is catered foremost towards bolstering the needs of the tourist rather than to addressing the wants of Emiratis or the needs of the non-Emirati resident population.

Aside from cultural considerations including the erosion of local identity and the failure of tourists in respecting local customs and moral values, mass tourism may also impact the quality of life and quality of place in other ways. Higher prices for goods and services, rising costs for real estate and land, increased traffic congestion and noise pollution, as well as increased competition between the tourist and resident for the same 
recreational venues and spaces are outcomes that might be expected if Dubai Vision 2020 comes to fruition. Therefore this study argues that sustainable tourism planning and development must be a central concern during the ongoing implementation phase of Dubai's strategic tourism vision. A sustainable tourism planning framework, it is argued, is one that seeks to maximize the benefits of tourism all the while minimizing the costs of this activity. In particular, such a framework recognizes the 'holistic' nature of tourism it must plan for the visitor as well as the resource - and, from a resource management perspective, it considers the social and cultural impacts of tourism throughout the planning process, ideally through the application of a modified environmental impact assessment procedure so that benefits are optimized and problems are minimized. An important planning policy strategy to reinforce positive impacts while mitigating negative ones involves encouraging community involvement in planning activities so that residents understand the tourism strategy and feel empowered in the decision making process. In short, thoughtful, culturally sensitive planning on the part of Dubai's tourism planners and developers is vital if future surveys are to avoid showing a problematic progression along the Irridex model.

\section{Conclusion}

With the backdrop of a recently declared strategic tourism vision, this paper sought to assess resident (Emirati) perceptions to tourism and to situate the survey findings using an appropriate conceptual model (Doxey Irridex model). The underlying goal was to gauge the critical level of tourists (i.e. number of tourists that exceeds the social and psychological carrying capacity of the city) in light of the planned doubling of an already substantial tourist presence. If the survey responses and applied conceptual model are of any indication then Dubai's tourism industry may continue to be expanded in the coming years without likely prompting widespread irritation and antagonism within the host population. That said, in spite of the current resident perceptions that generally view continued tourism development favourably, it should be recognized that uncontrolled tourism growth may eventually have a detrimental effect on quality of place and on the quality of life of residents (e.g. crowding, increased prices of goods and services, modified lifestyles). Thus we argue, as do others, that tourism planning should not be primarily oriented towards attracting a mass of tourists (Osborne \& Kovacs, 2008) or in catering primarily towards the needs of a select group of visitors in search of high-quality tourist experiences. Indeed, several questions emerge from our survey-based study, which we believe tourism planners and policy makers should regularly consider in the course of their work: How many more tourists should be sought and what are the services that will be required? What kind of tourist is most desired? And, how will further tourism development ultimately serve to improve the lifestyles of the local residents? Given the rapid rise in the number of international and domestic tourists and their accompanied environmental and socio-cultural impacts on tourist destinations worldwide, it is crucial that these questions be seriously addressed. It is also crucial that the social carrying capacity of the tourist destination be carefully explored through sound research that addresses resident attitudes and perceptions. Tourism planners should not only be cognizant of the benefits that may accrue from increased tourism but also of the 
potentially undesirable implications that uncontrolled growth may have on the quality of life of the citizens that they serve.

\section{References}

Nagraj, A. 2014. Exclusive interview: HE Helal Saeed Al Marri, Dubai's tourism chief. http://gulfbusiness.com/2014/05/exclusive-interview-helal-saeed-al-marri-dubais-tourismchief/\#.VD7ixleGeBs

Al-Qaydi S, Al Ketbi A, Al Olama H, Rida N. 2005. Geography of UAE. United Arab Emirates University Publications.

Bagaeen, S. 2007. Brand Dubai: The instant city; or the instantly recognizable city. International Planning Studies 12(2): 173-197.

Balakrishnan, M.S. 2008. Dubai - a star in the east: A case study in strategic destination branding. Journal of Place Management and Development 1(1): 62-91.

Boniface B, Cooper C. 2005. Worldwide destinations: The geography of travel and tourism. Elsevier.

Doxey, G.V. 1975. A causation theory of visitor-resident irritants: Methodology and research inferences. The impact of tourism: Travel Research Association, 6th Annual Conference Proceedings (195-198). San Diego, September 8-11.

Doxey, G.V. 1976. When enough's enough: The natives are restless in Old Niagara. Heritage Canada 2(2): 26-27.

Department of Tourism and Commerce Marketing (DTCM) .2013. Dubai welcomes over 7.9 million visitors in first mine of 2013.2 Available at http://chfr.dubaixperts.com/index.php?option=com_content\&view $=$ article\&id= $741 \% 3$ Adubai-welcomesover-79-million-visitors-in-first-nine-months-of-2013\&catid=1\%3Alatest-newsDTCM.

EIU. 2006. Country profile 2006. Economist Intelligence Unit: London.

Elessawy, F., Zaidan, E. (2014). Living in the Move: Impact of Guest Workers on Population Characteristics of the United Arab Emirates (UAE). The Arab World Geographer, 17(1): 2-23.

Erisman H.M. 1983. Tourism and cultural dependency in the West Indies. Annals of Tourism Research 10(3): 337-361.

Giddens A. 1994. Beyond left and right: The future of radical politics. Stanford

University Press: Stanford, CA.

Government of Dubai. 2013. Dubai welcomes over 7.9 million visitors in first nine months of 2013. Available at http://pr.dubaitourism.ae/2013/11/07/dubai-welcomes-over-7-9-million-visitors-infirst-nine-months-of-2013/

Government of Dubai. 2015. Dubai in figures. Available at http://www.dsc.gov.ae/en/pages/home.aspx

Govers R, Go F.M. 2005. Projected destination image online: Website content analysis of pictures and text. Information Technology \& Tourism 7: 73-89.

Govers R, Go F.M. 2009. Place branding: Glocal, virtual and physical identities, constructed, imagined and experienced. Macmillan: Basingstoke UK.

Henderson J.C. 2006. Tourism in Dubai: Overcoming barriers to destination development. International Journal of Tourism Research 8(2): 87-99.

Henderson, J.C. 2007. Destination development: Singapore and Dubai compared. Journal of Travel \& Tourism Marketing 20(3/4): 33-45.

Jordan-Bychkov T.G, Domosh M, Neumann R.P, Price P.L. 2014. Fundamentals of the human mosaic: A thematic introduction to cultural geography. $2^{\text {nd }}$ edition. Freeman: New York.

Junemo M. 2004. Let's build a palm island! Playfulness in complex times. In Sheller M, Urry J. (eds.) Tourism mobilities: Places to play, places in play (181-191). Routledge: London.

Kerstetter D.L, Bricker K.S. 2012. Relationship between carrying capacity of small island tourism destinations and quality-of-life. In Uysal M. et al. (eds.) Handbook of tourism and quality-of-life research: Enhancing the lives of tourists and residents of host communities (445-462). Springer: London.

Lundberg D.E. 1974. Caribbean tourism: Part 2. Social and racial tensions. Cornell H.R.A. Quarterly 15(1): 82-87.

MasterCard Global Destination Cities Index. (2014). Available at http://newsroom.mastercard.com/wp content/uploads/2014/07/Mastercard_GDCI_2014_Letter_Final_70814.pdf

Mathieson A, Wall G. 1982. Tourism: Economic, physical and social impacts. Longman: Harlow. 
McIntosh R.W, Goeldner C.R, Ritchie J.R. 1995. Tourism: Principles, practices, philosophies (7th edition). John Wiley \& Sons: New York.

Meethan K. 2011. Dubai: An exotic destination with a cosmopolitan lifestyle. In Mosedale J. (ed.), Political economy of tourism: A critical perspective (175-188). Routledge: London.

Mitchell C.J.A, Wall S. de. 2009. Revisiting the model of creative destruction: St. Jacobs, Ontario, a decade later. Journal of Rural Studies 25: 156-167.

Nunez T.A. 1963. Tourism, tradition, and acculturation: Weekendismo in a Mexican village Ethnology 2(3): 347-352.

Osborne B.S. 2002. Moose Jaw's 'great escape': Constructing tunnels, deconstructing heritage, marketing places. Material History Review 55: 16-28.

Osborne B.S, Kovacs J.F. 2008. Cultural tourism: Seeking authenticity, escaping into fantasy, or experiencing reality. Choice 45(6): 927-937.

Park H. yu. 2010. Heritage tourism: Emotional journeys into nationhood. Annals of Tourism Research 37(1): 116-135.

Park H. yu. 2011. Shared national memory as intangible heritage: Re-imagining two Koreas as one nation. Annals of Tourism Research 38(2): 520-539.

Park H. yu, Stephenson M.L. 2007. A critical analysis of the symbolic significance of heritage tourism. International Journal of Excellence in Tourism, Hospitality and Catering 1(2): 34-60.

Pizam A, Milman A. 1984. The social impacts of tourism. Industry and Environment 7(1): 11-14.

Ratz T. 2000. The socio-cultural impact of tourism: The case of Lake Balaton. Research Support Scheme. Available at http://rss.archives.ceu.hu/archive/00001132/01/140.pdf

Ratz T. 2003. Residents' perceptions of the socio-cultural impact of tourism at lake Balaton, Hungary. In Richard G, Hall D (eds.) Tourism and sustainable community development. Routledge.

Reisinger Y. 1994. Social contact between tourists and hosts of different cultural backgrounds. In Seaton A.V. et al. (eds.) Tourism: The state of art (743-754). John Wiley \& Sons: Chichester, UK.

Sharpley R. 2008. Planning for tourism: The case of Dubai. Tourism and Hospitality Planning and Development 5(1): 13-30.

Smith B. 2010. Scared by, of, in, and for Dubai. Social and Cultural Geography 11(3): 263-283.

Soper A.K. 2007. Developing Mauritianness: National identity, cultural heritage values and tourism. Journal of Heritage Tourism 2(2): 94-109.

Stephenson M.L. 2014. Tourism, development and 'destination Dubai': Cultural dilemmas and future challenges. Current Issues in Tourism 17(8): 723-738.

Stephenson M, Ali-Knight J. 2010. Dubai's tourism industry and its societal impact: Social implications and sustainable challenges. Journal of Tourism and Cultural Change 8(4): 278-292.

Turner L, Ash J. 1975. The golden hordes: International tourism and the pleasure periphery. Constable \& Robinson Limited: London.

UNEP (United Nations Environment Programme). 2014. Negative socio-cultural impacts from tourism: Change or loss of indigenous identity and values. Available at:

http://www.unep.org/resourceefficiency/business/sectoralactivities/tourism/factsandfiguresabouttourism/ impactsoftourism/socio-culturalimpacts/negativesocioculturalimpactsfromtourism/tabid/78781/default.aspx

Wall G, Mathieson A. 2006. Tourism: Change, impacts, and opportunities. Pearson Prentice Hall: Toronto.

Zaidan, E. (2015a). Tourism Planning and Development in Dubai: Developing Strategies and Overcoming Barriers. In Kozak, M, and N. Kozak, Tourism Development. Cambridge Scholars Publishing.

Zaidan, E. (2015b). Tourism shopping and new urban entertainment: a case study of Dubai. Journal of Vacation Marketing, 22, 1: 29-41.

Zaidan, E. (2016). The impact of cultural distance on local resident's perception of tourism development: The case of Dubai in UAE. Tourism, V64, 1: 109-126. 